\title{
Conduction of Academic Examination in the University Campus by the Medicine College during Coronavirus Disease 2019 Pandemic: Elaboration of Precautionary Methods
}

Ruqaih Alghsham $^{1}$ (D), Zafar Rasheed ${ }^{2}$ (D) Ali Shariq ${ }^{3}$ D, Sharifa Alduraibi ${ }^{4}$ (D), Ahmed A. Ahmed ${ }^{5}$, Mohammad Alkhowailed ${ }^{6}$ (D)

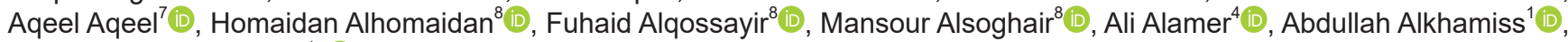
Waleed Al Abdulmonem ${ }^{1 *}$ (i)

${ }^{1}$ Department of Pathology, College of Medicine, Qassim University, Buraidah, Saudi Arabia; 2Department of Medical Biochemistry, College of Medicine, Qassim University, Buraidah, Saudi Arabia; 3Department of Microbiology, College of Medicine, Qassim University, Buraidah, Saudi Arabia; 4Department of Radiology, College of Medicine, Qassim University, Buraidah, Saudi Arabia; 5Research Center, College of Medicine, Qassim University, Buraidah, Saudi Arabia; 6Department of Dermatology, College of Medicine, Qassim University, Buraidah, Qassim, Saudi Arabial; 7Department of Pediatrics, College of Medicine, Qassim University, Buraidah, Saudi Arabia; 8Department of Family and Community Medicine, College of Medicine, Qassim University, Buraidah, Saudi Arabia

Edited by: Sasho Stolesk Citation: Alghasham R, Rasheed Z, Shariq A, Alduraibi S, Ahmed AA, Alkhowailed M, Aqeel A, Alhomaidan $\mathrm{H}$, bdulmonem W. Conduction of Academic Examination the University Campus by the Medicine College during in the Univevirus Campus by the Medicine College durin Precautionary Methods. Open-Access Maced J Med Sci. 2022 Feb 20; 10(E):248-253. https://doi.org/10.3889/oamjms.2022.8163 Keywords: Precautionary methods; Coronavirus diseas 2019; Medical students; Academic examination; University campus; Tawakkalna software of Pathology, College of Medicine, Qas, Un Univer College of Medicine, Qassim University, E-mail: dr.waleedmonem@quedusa Received: 04-Dec-2021 Revised: 09-Jan-2022 Accepted: 10-Feb-2022 Copyright: @ 2022 Ruqiah Alghasham, Ahmed A. Ahmed, Mohammad Alkhowailed, Aqeel Aqeel, Homaidan Alhomaidan, Fuhaid Alqossayir, Mansour Alsoghair, Ali Alamer, Abdullah Alkhamiss, Funding: This research did not receive any financial suppo Competing Interest: The authors have declared that no competing interest exist Open Access: This is an open-access article distributed under the terms of the Creative Commons AttributionNonCommercial 4.0 International License (CC BY-NC 4.0)

\begin{abstract}
AIM: This study was undertaken to elaborate the precautionary methods taken by the College of Medicine of Qassim University for conduction of students' academic examinations (exams) in the university campus during the
\end{abstract} coronavirus disease 2019 (COVID-19) pandemic.

METHODS: This study was conducted on undergraduate medical students $(n=674)$ from September 2020 to April 2021 in the College of Medicine at Qassim University. The switch into conducting examinations within the center was managed by the examination committee. Multiple online workshops were conducted to the staff and students regarding the precautionary measures and the examination procedures to prevent the transmission of the disease among students and staff. New guidelines for undertaking the examinations were designed and implemented at the examination centers in the university campus during COVID-19 pandemic.

RESULTS: All the examinations were conducted in a satisfactory manner under one roof under the supervision of the invigilation team within the examination center located in the university campus. The strict implementation of precautionary guidelines and the crucial steps to prevent the spread of coronavirus facilitated the accomplishment of this vital task in a smooth manner with no case of COVID-19 reported in any of the staff or students who participated in this activity.

CONCLUSION: This study revealed the precautionary methods and steps undertaken by the college of medicine, Qassim University in terms of conducting examinations within campus. If implementation of precautionary measures should be carried out in a proper manner then it is possible to conduct examinations under one roof.

\section{Introduction}

Coronavirus disease 2019 (COVID-19) is an infectious disease that is caused by severe acute respiratory syndrome coronavirus 2 (SARSCoV2) [1]. The name of this novel virus was coined on February 11, 2020 by the International Committee on Taxonomy of Viruses (2.ICTV) [2]. This virus belongs to Coronaviridae family, from which previously several viruses emerged that were accountable for a series of global epidemics [3]. These include severe acute respiratory syndrome-related coronavirus (SARSCov1) and Middle East respiratory syndrome-related coronavirus (MERS Cov); however none of these virus resulted in a global pandemic. As observed by the novel SARS-CoV2 affecting nearly every country, bringing the world to a pause by shattering down all the insolence of modern-day civilization making human realize that still there are lots of concealed catastrophic challenges which are to be faced on this planet [4]. After being first detected in Wuhan province, which is an industrial hub of People's Republic of China, this virus rapidly spread throughout the world implementing its cataclysmic effects [5], [6]. To avert, people from getting infected by this novel infection, various prevention measures and guidelines were introduced by the relevant authorities. These ranged from simple precautions such as wearing 
masks, gloves, and undergoing precautions to regional or countrywide lock downs and travel restrictions to curb down the infection rate [5], [6]. One of the most crucial tasks during this pandemic was regarding the continuity of the education process in an unfeigned manner. Traditional mode of teaching by educational institutes requires gathering of a large number of students under the same roof, continuing this practice would serve as a potential source of transmission of this virus among the students as well as in the community [7]. For this purpose, distance-based learning was implemented as a mode of teaching with aid of digital technology and virtual learning tools; however, a bigger challenge regarding the academic assessment of students by conducting examinations [8]. The major hurdle in conducting the online examination was transparency as it was very multifarious to evaluate that the students are not being deceitful during the examination. Keeping this predicament under view of the administration of the College of Medicine, Qassim University decided to conduct the examination in the university campus. The students were requested by the college administration to visit university campus and the examination was conducted under supervision of college faculty, hence, assuring the intelligibility. In this aspect, the present study was designed to explore the preventive methods taken by the College of Medicine, Qassim University, while conducting students' academic examinations in the university campus during COVID-19 pandemic.

\section{Methods}

\section{Study participants and announcement of general guidelines}

This study was performed on undergraduate medical students $(n=674)$ from September 2020 to April 2021 in the College of Medicine at Qassim University in KSA during their academic year examination in COVID19 era. The general guidelines were virtually announced before conduction of examinations. All the approved regulations and instructions of the examinations were announced on the virtual site that was Blackboard. It included the general seating plans, locations, and total number of students, which had been received from the Central Examination Committee (CEC) - to all the students of that block/course at least 3 working days before the start of the examination. Ensuring that the chief invigilator received the answer sheets, attendance sheet, and examination booklets from the CEC at least 2 working days before the start of the examination.

\section{Managing students in the examination center}

The average number of students in each level was 120 in total, with the number male students approximately ranging in between 80 and 90 and female students about $35-50$ in total. The students were divided into small groups ranging from 10 to 12 students allocated in each. The students were informed online regarding their seat number a day before the examination by posting the seating arrangement on the virtual platform called blackboard. The management of students in groups at examination centers during COVID-19 pandemic are summarized in Figure 1. To avoid crowd gathering in the examination campus, the invigilation faculty and the students were requested to arrive approximately $1 \mathrm{~h}$ before the conduction of examination. Every person proceeding toward the examination hall was directed by arrow signs to avoid any human interaction during the arrival. Core body temperature of every person entering the examination venue was assessed by the aid of digital thermometers and it was made assured that the digital thermometers are calibrated and up to the mark on daily basis. On entering the main corridor of examination, hall students were asked to stand in specially created rows on which stickers for social distancing were pasted on the floor at a distance of 3 feet apart. Each row comprises 10-12 students, on completion of the number of students in the row, they were asked to move ahead toward their examination room under supervision of administrative personnel who assured the safe physical distance in between each student during the whole process.

\section{Use of personal protective equipment}

All the examination invigilation team and students were explained through infection control protocols required for preventing transmission of COVID-19 through email as well as on virtual platforms. It was made mandatory for every person who is entering the examination center to wear gloves and a mask. In case, any student or invigilation team member fails to remember or his/her mask or gloves that were damaged, new ones were provided by university administration. Furthermore, it was made mandatory to wear a mask in the proper manner by covering the nose and mouth according to the international guidelines.

\section{Environmental disinfection}

The examination equipment, floor, and seats were disinfected with ethanol-based cleaning solutions on a daily basis before initiation of examination and after the examination ended under the supervision of trained administrative staff. Wall mounted ethanolbased hand sanitizers were provided after every few meters. In wash rooms, liquid soap and hand towels were provided. Moreover, frequent flyers and charts elaborating the importance of hand hygiene, social distancing, and awareness about COVID-19 were pasted. 


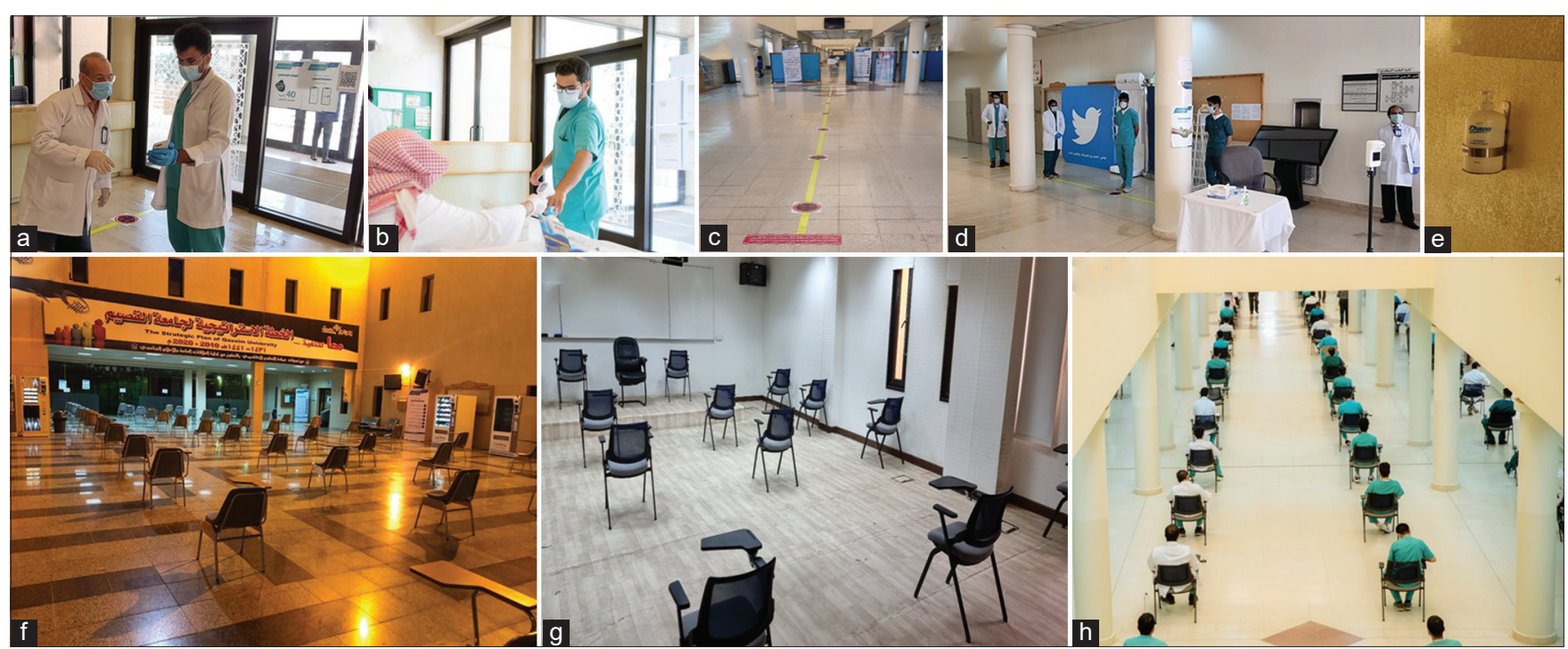

Figure 1: Management of medical students' at the examination center of College of Medicine, Qassim University during COVID-19 pandemic. (a) Checking of vaccination status at the entrance gate through Tawakalna application. (b) Checking body temperature at the entrance gate. (c) Marked row for students waiting before entering the examination hall. (d) Waiting for students in rows to enter the examination hall. (e) Hand sanitizer bottle in the wall of the examination hall. (f) Sitting arrangement of students in the examination hall. (g) Sitting arrangement of students in the classroom. (h) Students sitting in the examination hall

\section{Maintaining social distancing}

In the examination venue, social distancing was austerely implemented. Seating arrangement was done in the manner, the distance between each chair was 3 feet or more and students were made to sit on alternate chairs. The chief invigilator had the right to ask a student to leave the examination under the following circumstances: If a student was caught breaching of University Examination Regulation and/or precautionary measures; if there was an evidence of student's cheating such as possession of unauthorized materials; students misbehavior such as disturbing and distracting other students; and if a student does not follow the announced precautionary measurements of COVID-19 pandemic.

\section{Distribution of examination material among students and conduction of examination}

The examination consisted of two sections. The first section is the MCQ section, which is conducted by providing students with a question paper and students mark the correct option on a specific answer sheet which is checked through software. The second section of examination comprises an OSPE section, in which, the students are shown pictures and asked to write down the answers on answer booklet. The chief invigilator (with the presence of two other invigilators faculty) had to open the examination envelopes only at examination venue 15 min before the examination. At the beginning of the examination, the chief invigilator requested that all students have to check their examination booklet and ensure that no page is missing. If there is any discrepancy or a missing page, he/she should inform the CEC immediately and the inappropriate examination materials should be replaced as soon as possible by a correct copy. Students were asked to mention their identification number and name on the answer sheet. Attendance of students was obtained by viewing the identification card and the evaluator marked the student present. Students were not permitted to leave the examination venue before $30 \mathrm{~min}$ of the start of the theoretical examination and till end of the practical exams (OSPE/OSCE). After the examination was over, the students had to leave the examination venue in an organized manner in accordance with the arrangement prepared by the Precautionary Measures Committee.

\section{Use of technology in university campus}

Every person entering the examination venue was asked to show his present status regarding immunization, present, or past infection through a digital application named "Tawakkalna," which was made mandatory in the Kingdom of Saudi Arabia and every citizen was obliged to have it in his cellular device. After the checking of the status, the students were asked to turn-off their cellular device. Moreover, the implementation of preventive protocols was observed with the help of surveillance cameras.

\section{Checking of examination papers}

At the end of the examination, the chief invigilator collected and counted the answered and unanswered sheets and delivered them to the CEC. The invigilators wore protective masks and gloves all the time and especially when dealing with the answer sheets and examination booklets as well as during the whole period of the examination. The CEC kept 
the examination papers in a secure location for $72 \mathrm{~h}$ after which the examination checking was initiated. The teaching staff responsible for checking the paper would be communicated through email and was specified regarding the date, time, and venue of checking paper. During checking, implementation of social distancing and wearing of masks and gloves was observed.

\section{Results and Discussion}

This is first study from Saudi Arabia to explore the precautionary methods for the conduction of examination in the university campus during COVID-19 pandemic. The outcomes of this novel study demonstrated that all the examinations were conducted in a satisfactory manner under one roof under the supervision of an invigilation team within the examination center located in the university campus. The strict implementation of precautionary guidelines and the crucial steps to prevent the spread of coronavirus facilitated the accomplishment of this vital task in a smooth manner with no case of COVID-19 reported in any of the staff or students who participated in this activity. During the COVID-19 pandemic, the adoption of virtual learning was the only safe and reasonable educational option that ensured students' engagement along with fulfilling their knowledge gaps as well as competencies of the health professional educators [9], [10], [11]. However, to provide high standards of medical education, it was mandatory not to compromise on merit so that the students who would be practicing as the future health practitioners would not be lacking the skills and knowledge required to deliver quality health management to the community [12], [13]. To accomplish this goal, the Qassim University administration after extensive meetings has decided to conduct examinations within the campus. This was a challenging task as the mode of transmission of COVID19 which is through droplet spread can abruptly be transferred from an infected person to other people in the vincity [14], [15]. To tackle this challenge, guidelines and protocols were formulated after consultation with expertise and workshops were conducted to train the staff who would be responsible for conducting the examinations. Implementation of these policies and protocols was the fundamental element to bring these on paper policies into real world scenarios as a minimal breach at any level could shatter down the whole plan. As described in the method section, protocols were executed and preparations were done days before the examination date starting from student and staff awareness and continuous recapitulation of protocols established for COVID-19 precaution. Implementing the steps as mentioned in the guideline can assure a corona free environment within the academic facility, in which, the academic staff and students can carry their academic and intellectual activities without the risk of being infected. As mentioned above, the utilizing digital technology by viewing the Tawakkalna application and at the spot initial monitoring of temperature assisted in screening of potential infected cases. Tawakkalna application is a digital application which is made compulsory by Saudi Arabia law that every person should have it in their cellular device [16]. It consists of some vital information regarding the health status of the person showing if someone was infected in the past or has been recently infected as it has now well established that an early prediction of COVID-19 cases is a key to stop or decline the progression of this viral transmission [17]. Therefore, Tawakkalna application plays an important role for performing these examinations in the campus. Moreover, this application also presents the immune status of the person regarding that if anyone is non-immunized, partially immunized, or completely immunized by the vaccine. Therefore this mobile application provides an effective way to screen the immunization status of people. Moreover, spot checking of temperature with the aid of a digital thermometer was another effective way to identify the potentially infective population. Although various studies are there, asymptomatic carriers of COVID-19 are also present [18], [19]. These people do not show signs of active infection such as fever and cough and so temporal temperature monitoring cannot detect them as there is no core body temperature rise and so can be source of transmission of infection in the surroundings. However, monitoring the digital Tawakkalna application serves as an effective tool to prevent such spread as on Tawakkalna application, the immunization data are also available so only those who are fully vaccinated by two doses of anti-corona vaccine or showing immunized status by recent recovered infection are allowed to enter the premises. Hence, the chances of spread of infection by asymptomatic population may have greatly reduced. One of the fundamental steps in prevention of spread of coronavirus is by maintaining social distance and avoiding direct touch to inanimate objects. It was made compulsory for any person entering the academic vincity to wear gloves as well as a mask. The seating arrangement in our institute was made in accordance with the least possible risk of transmitting coronavirus from person to person. A distance of at least $3 \mathrm{~m}$ was kept in between two consecutive seating or standing spaces. One of the important risk factors which is observed in various studies was mingling of people and avoiding social distancing [20]. Particularly, when the examination was over, students try to evacuate the examination center in hurry as well as discussing examination questions with their fellow colleagues. This issue was particularly stressed on and to avoid any transmission during this period, students were asked to leave the examination venue one at a time and in a specific order by maintaining a social distance of $3 \mathrm{~m}$ apart. By following the preventive guidelines in our institute, we can mention with surety that if proper 
implementation of preventive measures designed to avoid spread of COVID-19 should be pursued the chance of spread of COVID-19 can be effectively controlled.

\section{Conclusion}

This study revealed the precautionary methods and steps undertaken by the College of Medicine, Qassim University for the conducting academic year examination within university campus. We concluded that if implementation of precautionary methods should be carried out in proper manners then it is possible to conduct any types of students' activities under a roof even under COVID-19 pandemic circumstances.

\section{Acknowledgments}

The authors gratefully acknowledged Dr. Ahmad Alamro, the previous Dean of College of Medicine, Qassim University and Dr. Faisal I. Almohaileb, the present Dean of College of Medicine, Qassim University for the management of examinations in the university campus. The authors also thank the College of Medicine Invigilation Committee, the Learning Resource Unit, the Biosafety Unit, and all students and staff members for their active participation in examinations during the pandemic. Finally, the authors also thank Mr. Omar Al-Hussain for helping the staff and students to manage social distancing.

\section{Authors' Contributions}

RA, AS, RA, MA, AAAI, SKA, HTA, MA, AA, $F A$, and $A S A$ were involved in conceptualization, data collection and interpretation, and manuscript drafting. Whereas, ZR, AAA, and WAA were participated in the data interpretation, validation, and manuscript drafting. All authors read and approved the final version of this article.

\section{References}

1. Umakanthan S, Sahu P, Ranade AV, Bukelo MM, Rao JS, Abrahao-Machado LF, et al. Origin, transmission, diagnosis and management of coronavirus disease 2019 (COVID-19).
Postgrad Med J. 2020;96(1142):753-8. https://doi.org/10.1136/ postgradmedj-2020-138234

PMid:32563999

2. ICTV. Naming the 2019 Coronavirus. Available from: https://talk. ictvonline.org [Last accessed on 2020 Sep 20].

3. Alkhowailed MS, Alqossayir F, Rasheed Z, Alkhamiss A, Alsalloom AA, Ali $A$, et al. Comprehensive review on novel COVID-19: A Saudi perspective. Arab J Basic Appl Sci. 2020;27(1):480-92. https://doi.org/10.1080/25765299.2020.185 2731

4. Alabdulmonem W, Shariq A, Rasheed Z. COVID-19: A global public health disaster. Int J Health Sci (Qassim). 2020;14(3):7-8. PMid:32536842

5. Burki T. Outbreak of coronavirus disease 2019. Lancet Infect Dis. 2020;20(3):292-3. https://doi.org/10.1016/ S1473-3099(20)30076-1

PMid:32078809

6. Alkhowailed M, Shariq A, Alqossayir F, Alzahrani OA Rasheed Z, Al Abdulmonem W. Impact of meteorological parameters on COVID-19 pandemic: A comprehensive study from Saudi Arabia. Inform Med Unlocked. 2020;20:100418. https://doi.org/10.1016/j.imu.2020.100418

PMid:32875061

7. Bazant MZ, Bush JW. A guideline to limit indoor airborne transmission of COVID-19. Proc Natl Acad Sci U S A. 2021;118(17):e2018995118. https://doi.org/10.1073/ pnas. 2018995118

PMid:33858987

8. Alkhowailed MS, Rasheed Z, Shariq A, Elzainy A, El Sadik A, Alkhamiss A, et al. Digitalization plan in medical education during COVID-19 lockdown. Inform Med Unlocked. 2020;20:100432. https://doi.org/10.1016/j.imu.2020.100432 PMid:32959020

9. Khalil R, Mansour AE, Fadda WA, Almisnid K, Aldamegh M, Al-Nafeesah $A$, et al. The sudden transition to synchronized online learning during the COVID-19 pandemic in Saudi Arabia: A qualitative study exploring medical students' perspectives. BMC Med Educ. 2020;20(1):285. https://doi.org/10.1186/ s12909-020-02208-z PMid:32859188

10. Puljak L, Čivljak M, Haramina A, Mališa S, Čavić $D$, Klinec D, et al. Attitudes and concerns of undergraduate university health sciences students in Croatia regarding complete switch to e-learning during COVID-19 pandemic: A survey. BMC Med Educ. 2020;20(1):416. https://doi.org/10.1186/ s12909-020-02343-7

PMid:33167960

11. Elzainy A, El Sadik A, Al Abdulmonem W. Experience of e-learning and online assessment during the COVID-19 pandemic at the College of Medicine, Qassim University. J Taibah Univ Med Sci. 2020;15(6):456-62. https://doi. org/10.1016/j.jtumed.2020.09.005

PMid:33106752

12. Parkes RS, Barrs VR. Interaction identified as both a challenge and a benefit in a rapid switch to online teaching during the COVID-19 pandemic. J Vet Med Educ. 2021;48:629-35. https:// doi.org/10.3138/jvme-2020-0063 PMid:33493099

13. Al-Balas $\mathrm{M}$, Al-Balas $\mathrm{HI}$, Jaber $\mathrm{HM}$, Obeidat $\mathrm{K}$, Al-Balas $\mathrm{H}$, Aborajooh EA, et al. Distance learning in clinical medical education amid COVID-19 pandemic in Jordan: Current situation, challenges, and perspectives. BMC Med Educ. 2020;20(1):341. https://doi.org/10.1186/s12909-020-02257-4 PMid:33008392

14. Dieck-Assad G, Peña OI, Rodríguez-Delgado JM. Evaluation 
of emergency first response's competency in undergraduate college students: Enhancing sustainable medical education in the community for work occupational safety. Int $\mathrm{J}$ Environ Res Public Health. 2021;18(15):7814. https://doi.org/10.3390/ ijerph18157814

PMid:34360107

15. Seifert $T$, Becker $T$, Büttcher AF, Herwig N, Raupach $T$. Restructuring the clinical curriculum at University Medical Center Göttingen: Effects of distance teaching on students' satisfaction and learning outcome. GMS J Med Educ. 2021;38(1):Doc1. https://doi.org/10.3205/zma001397

PMid:33659606

16. Tawakkalna Application. Available from: https://ta.sdaia.gov.sa/ en/index [Last accessed on Sep 2021 20].

17. Khodeir MM, Shabana HA, Alkhamiss AS, Rasheed Z, Alsoghair M, Alsagaby SA, et al. Early prediction keys for COVID19 cases progression: A meta-analysis. J Infect Public Health.
2021;14(5):561-9. https://doi.org/10.1016/j.jiph.2021.03.001 PMid:33848885

18. WeiWE, LiZ, Chiew CJ, Yong SE, Toh MP, Lee VJ. Presymptomatic transmission of SARS-CoV-2 Singapore, January 23-March 16, 2020. MMWR Morb Mortal Wkly Rep. 2020;69(14):411-5. https:// doi.org/10.15585/mmwr.mm6914e1 PMid:32271722

19. He X, Lau EH, Wu P, Deng X, Wang J, Hao X, et al. Temporal dynamics in viral shedding and transmissibility of COVID-19. Nat Med. 2020;26(5):672-5. https://doi.org/10.1038/ s41591-020-0869-5

PMid:32296168

20. Kronbichler A, Kresse D, Yoon S, Lee KH, Effenberger $M$, Shin Jl. Asymptomatic patients as a source of COVID-19 infections: A systematic review and meta-analysis. Int J Infect Dis. 2020;98:180-6. https://doi.org/10.1016/j.jijid.2020.06.052 PMid:32562846 